\title{
Optimal Strategy to Mitigate the Effect of Fast Charging Electric Tram in Power Distribution
}

\author{
Nuttapol CHARTSUK and Boonruang MARUNGSRI ${ }^{*}$ \\ School of Electrical Engineering, Suranaree University of Technology, Thailand \\ ${ }^{*}$ Corresponding author
}

\begin{abstract}
Nowadays, electric vehicles (EVs) include electric tram becomes more popular with high promotion from the government. The advantage of EVs is no produces the pollution and environmentally friendly compared with the internal combustion engines. The fast charging EVs as the load of the power distribution system, the large-sized fast charging can bring an effect on the power distribution system. The energy storage systems (ESS) can operate as a generator to balance the power and reduce power load fluctuation. In this paper, the effect to public electric transportation tram fast charging in the power distribution system was studied by a focus on voltage profile and power loss. Optimal strategy of ESS for reducing the peak demand on the power distribution system and reactive power optimization for improving power quality was proposed. By the obtained results with ESS and reactive power, the efficiency and power quality of the power distribution system was enhanced.
\end{abstract}

Keywords-fast charging; optimal reactive power; energy management; peak shifting

\section{INTRODUCTION}

For the future trends, there is a high possibility for using EVs as public vehicles. The EVs can reduce an amount of greenhouse gas emissions and global air pollution when compared with internal combustion engines. The EVs includes all-electric transportation system such as electric tram for public mass transit. It can reduce traffic jam and low service fees. Fast charging electric tram is one of famous EVs for public transportation. However, the high power is required on the charger during charging mode. The disadvantages of EVs to the power distribution system are voltage loss, transformer overload, line low-voltage side overload, power loss, frequency drop (more injury in islanding mode), voltage unbalances (case of single phase), and harmonics current [1].

It is essential to find the solution of EVs by using fast charging ESS. The fast charging ESS can balance the power and can reduce fluctuation power of the load. Designing an appropriate ESS in the power distribution system is used for the energy management and the stability improvement of the power distribution system [2]. Alternately, reactive power can help improve the voltage regulation of a distribution system. The reactive power management is critically important for ensuring the quality of power delivery and the system stability in a power distribution system [3].

The effect of fast charging public electric transportation tram to the power distribution system focusing on voltage profile and power loss was studied in this paper. Optimal strategy of the ESS to reduce the peak demand on the power distribution system and the reactive power optimization for improving power quality was evaluated.

\section{Methodology}

\section{A. The Fast Charging Model}

The fast charging model of electric tram using the battery in this study is based on a battery charging characteristic. The charging characteristics of the typical Li-ion battery, the interval $0-T_{1}$ is the constant current interval and the increasing of charging float voltage. The interval $T_{1}-T_{2}$ is a continuous voltage interval and the decreasing of charging float current. The approximately model of charging battery in the interval 0 $-\mathrm{T}_{1}$ can be expressed as follows [4],

$$
v(t)=V_{n}\left(1-e^{-\frac{t}{\tau_{v}}}\right), i(t)=I_{n}
$$

The approximate models of charging battery in the interval $\mathrm{T}_{1}-\mathrm{T}_{2}$ are as follows,

$$
v(t)=V_{n}, i(t)=I_{n} e^{-\frac{t}{\tau_{v}}}
$$

Where $V_{n}$ is the nominal continuous voltage of tram battery. $\tau_{\mathrm{v}}$ and $\tau_{\mathrm{i}}$ are the time constant determined from the charging voltage and charging current curves. The constant current $\mathrm{I}_{\mathrm{n}}$ decreases until the battery reaches the full charge status. The instantaneous power of tram battery during the charging process can be expressed by,

$$
w(t)=w(t) v(t)=\left[\begin{array}{ll}
\int_{T_{1}}^{T_{2}} V_{n} I_{n}\left(1-e^{-\frac{t}{\tau_{v}}}\right) \\
\int_{T_{1}}^{T_{2}} V_{n} I_{n} e^{-\frac{t}{\tau_{v}}}
\end{array}\right] ; 0 \leq t \leq T_{1}
$$

The total energy of electric tram charging and the nominal value of charging current of electric tram can be calculated by, 


$$
W=\int w(t) d t \int_{0}^{T_{1}} V_{n} I_{n}\left(1-e^{-\frac{1}{T_{n}}}\right) d t+\int_{T_{1}}^{T_{2}} V_{n} I_{n} e^{-\frac{1}{t_{n}}} d t=K I_{n}, I_{n}=\frac{k W h \times 10^{3} \times 3600}{K}
$$

The constant kWh is tram battery capacity in kilowatt-hour.

\section{B. Charging Station Model}

For the battery charging, $22 \mathrm{kV}$ of distribution system was step down to a low voltage level. At charging station, AC low voltage was converted to DC voltage for charging tram battery [5].

\section{Energy management (Peak shifting)}

An ESS is useful for the energy management and the stability improvement of the power distribution system. Peak shifting is a technique using to mitigate load fluctuations for enhancing the power quality which can manage by the ESS. The suddenly increasing, and the suddenly decreasing of load can be compensated by using the ESS. During normal condition, the ESS works like floating load. The ESS acts as energy absorber from the energy supply source at light load and assists the system for supply the energy at high load. The power balance without considering the line impedance can be calculated by [6],

$$
P_{D}=P_{D U t i l l i t y}+\sum_{i=1}^{N} P_{D G i}+P_{E S S}
$$

Where $\mathrm{P}_{\mathrm{D}}$ is the load demand power. $\mathrm{P}_{\mathrm{DGi}}$ is the real power generated by each DG in the power distribution system. $\mathrm{P}_{\mathrm{ESS}}$ is the output of the ESS. $P_{\text {DUtility }}$ is the real power demand from Utility.

The reference output of the ESS can be calculated by

$$
P_{\text {ESSref }}=P_{D}-P_{\text {total } ;} P_{\text {total }}=P_{D U \text { tility }}+\sum_{i=1}^{N} P_{D G i}
$$

And the ESS is charging and discharging mode as the condition following:

$$
\left\{\begin{array}{c}
\text { Ch } \arg \text { ing; } P_{D}<P_{\text {total }} \text { or } P_{E S S r e f}<0 \\
\text { Discharging; } P_{D}>P_{\text {total }} \text { or } P_{\text {ESSref }}>0
\end{array}\right.
$$

The maximum output of the ESS is $P_{E S S, \max }>P_{D}-P_{\text {total }}$. Usually, peak shifting is based on load forecasting. The load forecasting can be provided the information for energy or power demand during peak time. Therefore, the ESS in the power distribution system must store the energy during valley period and support the power distribution system in the peak time. The principle of peak shifting is shown in Fig. I. The ESS must reduce the load to the desired $P_{\text {level }}$. The next day's load can be forecasted; the predicted demand can be defined by $P_{D}(t)$. Therefore, the required energy for the ESS during the peak time $\left(t_{a, \text { peak }}, t_{b, \text { peak }}\right)$ can be calculated by,

$$
E_{\text {peak }}=\int_{t_{a, \text { peak }}}^{t_{b, p e a k}}\left(P_{D}(t)-P_{\text {level }}\right) d t
$$

If the total energy needed for the ESS during the peak time is known, then the ESS must store enough energy before the peak period.

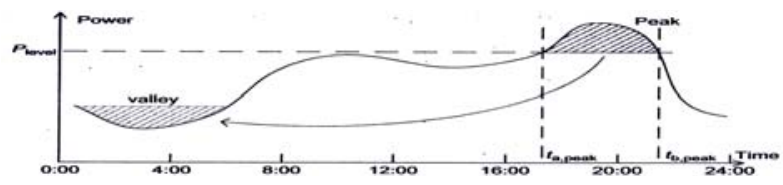

FIGURE I. THE PRINCIPLE OF PEAK SHIFTING

\section{SIMULATION RESULTS AND DISCUSSION}

The impact of fast charging on the public electric tram to the power distribution system was studied. IEEE 13-bus distribution network was used and was modified to simulate the proposed idea by MATLAB program. The modify single line diagram of IEEE 13-bus distribution network contains two feeding sources, is illustrated in Fig. II [7]. Three routes of the public electric tram were defined.

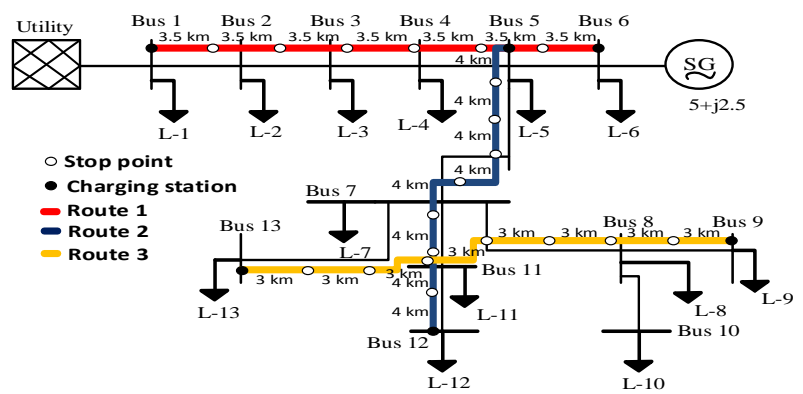

FIGURE II. ROUTES OF PUBLIC ELECTRIC TRANSPORTATION TRAM

For simulation the public electric transportation tram, essential data were defined. The electric tram speed was defined as $70 \mathrm{~km} / \mathrm{h}$. The electrical energy consumption was defined as $100 \mathrm{kWh} / \mathrm{h}$. The interval times of constant current and constant voltage charging were defined equal to 5 times time constant. The power factor of tram battery was set equal to 0.90 , and the capacity of tram battery was defined as $100 \mathrm{kWh}$ [4]. As shown in Fig. II, Three routes of the electric tram for public service were defined. Fast charging stations for route 1 were defined at bus 1 and bus 6 . Fast charging stations for route 2 were defined at bus 5 and bus 12. Fast charging stations for route 3 were defined at bus 9 and bus 13. The electric tram starts to service at 05.00 a.m. From the two adjacent charging stations, the route 1 takes around thirty minutes, the route 2 takes approximately thirty-five minutes, and the route 3 takes almost thirty minutes. The waiting time for next electric tram of each route is five minutes. During service, the electric tram must stop at stop station for one minute and fast charging at charging station for five minutes. The total charging energy can calculate from equation (4). The load curves of the typical days for 13 buses 
distribution network with fast charging electric tram are shown in Fig. III(a).

This section aims to mitigate the effect of fast charging electric tram to the power distribution system. To achieving this goal, three individual scenarios were proposed for improving power quality. These scenarios are as follows, Scenario 1: Without ESS and with reactive power, Scenario 2: With ESS

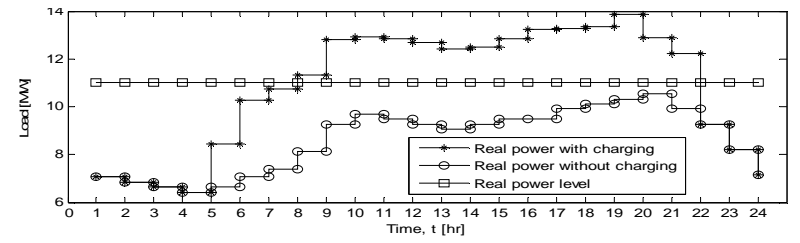

(a) and without reactive power, and Scenario 3: With ESS and reactive power.

As shown in Fig. III(a), the peak load with fast charging during 07.00 - 08.00 p.m. was the most worrisome period. During this time, the reactive power to improve power quality is considered by using DE method find the optimal size of reactive power at a bus. The flowchart of DE method to find optimal size and location of the reactive power is shown in Fig. IV(a).

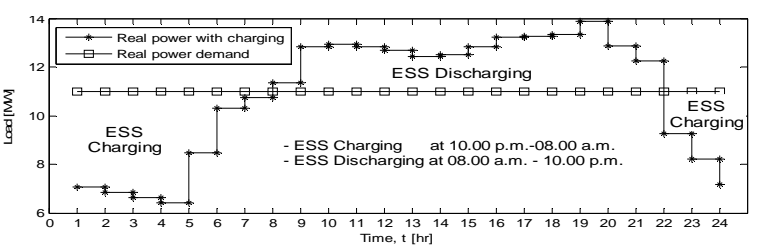

(b)

FIGURE III. (A) LOAD CURVES OF THE TYPICAL DAYS (B) AN ESS FOR ENERGY MANAGEMENT USING THE PRINCIPLE OF PEAK SHIFTING

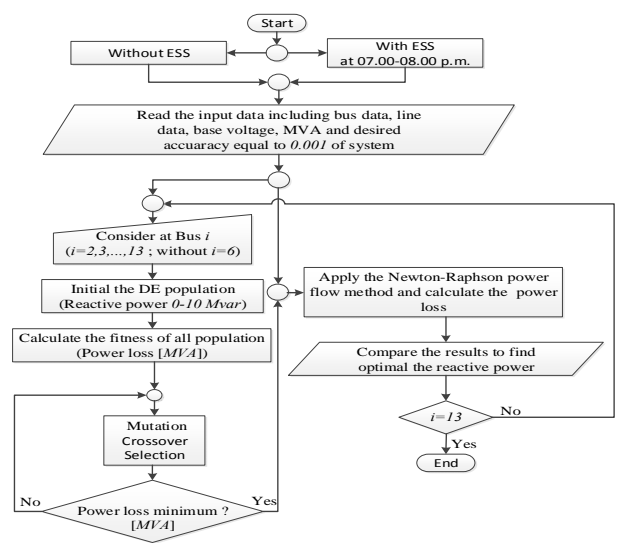

(a)

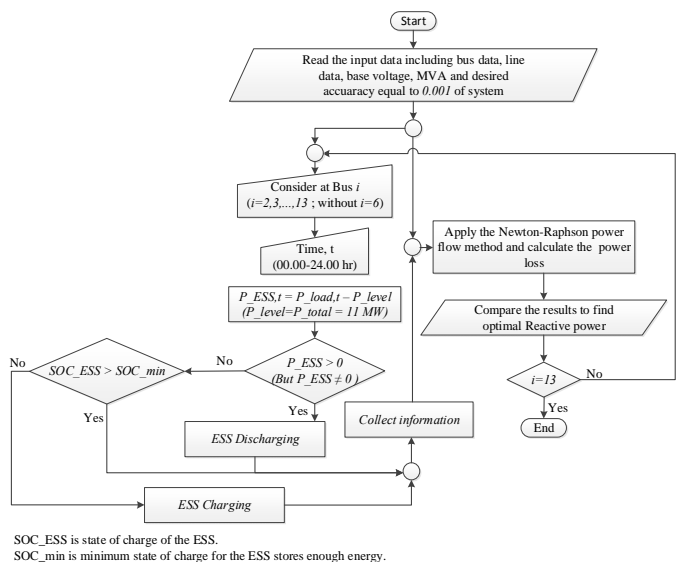

(b)

FIGURE IV. (A) FLOWCHART OF DE METHOD TO FIND THE OPTIMAL SIZE AND THE OPTIMAL LOCATION OF REACTIVE POWER (B) FLOWCHART TO FIND OPTIMAL SIZE AND OPTIMAL LOCATION OF THE ESS

Due to an ESS use for energy management and stability improvement, peak shifting for mitigate load fluctuations with fast charging and enhance power quality is shown in Fig. III(b). Optimal size and Optimal location of the ESS were determined by using Newton-Raphson method for power flow analysis via Matlab programming as a flowchart shown in Fig. IV(b). The results from DE method to find the optimal size and the location of the ESS via the reactive power is illustrated in Table I.

TABLE I. OPTIMAL LOCATION OF ESS AND REACTIVE POWER (Q)

\begin{tabular}{|c|c|c|c|c|c|c|c|c|}
\hline \multirow{2}{*}{$\begin{array}{c}\text { No. } \\
\text { Bus }\end{array}$} & \multicolumn{3}{|c|}{ Q without ESS } & \multicolumn{3}{c|}{ Q with ESS } & \multicolumn{2}{c|}{ ESS without Q } \\
\cline { 2 - 9 } & Size of Q & \multicolumn{2}{|c|}{ Power loss } & Size of Q & \multicolumn{2}{c|}{ Power loss } & \multicolumn{2}{c|}{ Power loss } \\
\cline { 2 - 9 } & Mvar & MW & Mvar & Mvar & MW & Mvar & MW & Mvar \\
\hline 2 & 1.497 & 1.077 & 0.845 & 1.412 & 0.569 & 0.448 & 7.016 & 3.399 \\
\hline 3 & 1.885 & 1.069 & 0.839 & 1.759 & 0.569 & 0.448 & 10.443 & 5.059 \\
\hline 4 & 1.986 & 1.069 & 0.839 & 1.840 & 0.569 & 0.448 & 10.474 & 5.074 \\
\hline 5 & 1.925 & 1.074 & 0.843 & - & - & - & 4.715 & 2.284 \\
\hline 7 & 4.483 & 1.028 & 0.806 & 4.218 & 0.542 & 0.427 & 12.081 & 5.852 \\
\hline 8 & 2.705 & 1.040 & 0.816 & 2.443 & 0.547 & 0.430 & 5.091 & 2.466 \\
\hline 9 & 1.996 & 1.049 & 0.822 & 1.801 & 0.551 & 0.433 & 5.196 & 2.517 \\
\hline 10 & 1.708 & 1.054 & 0.827 & 1.516 & 0.555 & 0.436 & 5.169 & 2.504 \\
\hline 11 & 2.472 & 1.046 & 0.820 & 7.392 & 0.582 & 0.458 & 5.032 & 2.438 \\
\hline 12 & 0.940 & 1.068 & 0.837 & 8.876 & 0.662 & 0.521 & 5.134 & 2.487 \\
\hline 13 & 7.499 & 1.066 & 0.838 & 3.076 & 0.549 & 0.432 & 4.974 & 2.410 \\
\hline
\end{tabular}

As obtained results in Table I, the best improvement is achieved while the ESS is located at bus 5. In this work, the reactive power 1.516 Mvar was selected to locate at bus 10 . When adding the ESS to the power distribution system, it is 
found that the optimal rated real power is $4.573 \mathrm{MW}$ and the energy capacity is $28.9 \mathrm{MWh}$, respectively. The ESS can perform peak shifting to reduce or eliminate the peak demand. The peak shifting plays a role to reduce the cost of the power distribution by reducing supplied power from the utility during peak time as shown in Fig. V. The ESS can store energy during light load and can provide the energy during peak load demand [6]. The power quality for different scenarios is shown in Fig. VI(a) and Fig.VI(b).

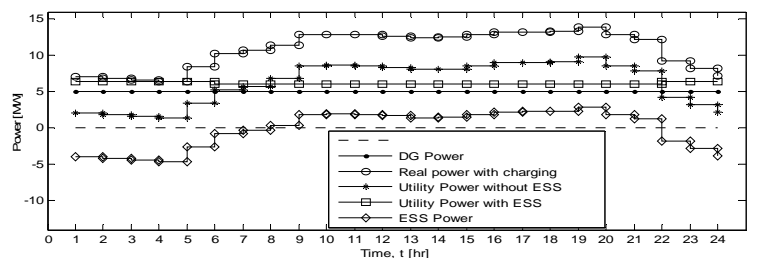

FIGURE V. THE REAL POWER PER DAY

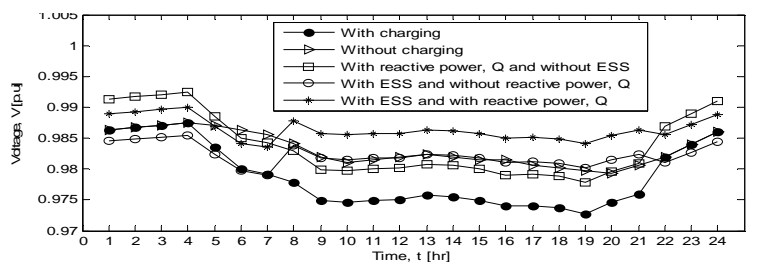

(a)

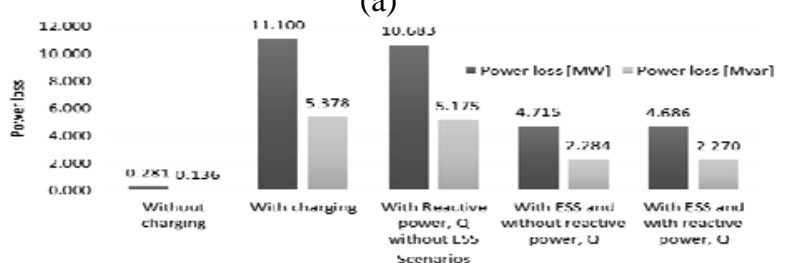

(b)

FIGURE VI. (A) COMPARATIVE RESULTS OF VOLTAGE PROFILE PER DAY (B) COMPARATIVE RESULTS OF POWER LOSS PER DAY

According to results in Fig. VI(a) and Fig.VI(b), the increase of total load demand due to electric tram resulting the effect both of power loss and voltage profile. The ESS and the optimal reactive power assist in reducing the power loss and voltage regulation of power distribution system.

\section{CONCLUSIONS}

The effect of fast charging electric tram to the power distribution system was studied in this paper. The optimal reactive power implemented to the reduction in power loss and improvement of voltage profile. The ESS plays a role in energy management and the stability improvements. Peak shifting is used mitigate load fluctuations with fast charging, and reduce the cost of the power distribution by lowering absorbed power from the utility during the peak time. The ESS and reactive power can provide the benefit to reduce power loss and voltage regulation.

\section{ACKNOWLEDGEMENT}

This work was supported by the Suranaree University of Technology.

\section{REFERENCES}

[1] Akhavan-Rezai, E., Shaaban, M. F., El-Saadany, E. F., Zidan, A. (2012). Uncoordinated charging impacts of electric vehicles on electric distribution grids, IEEE Power and Energy Society General Meeting. 16 (2012) 1-7.

[2] H. Lei, T. Zhang, Y. Liu, Y. Zha. Optimizing charging and discharging on a micro-grid with ESS and dynamic price, ICGEA. (2017) 85-89.

[3] M.A. Arif, M. Ndoye, G.V. Murphy, K. Aganah. A stochastic game framework for reactive power reserve optimization and voltage profile improvement, ISAP. (2017) 1-6.

[4] B. Boribun, P. Paolaor, T. Kulworawanichpong. Impact of electric bus charging in power distribution systems, ISIE. (2013) 1-6.

[5] B. Pea-Da, S. Dechanupaprittha. Impact analysis of fast charging to voltage profile in PEA distribution system by Monte Carlo simulation, ICITEE. (2015) 204-208.

[6] D.W. Gao. Energy storage for sustainable microgrid, London, 2015.

[7] A. Aref, M. Davoudi, F. Razavi, M. Davoodi. Optimal DG Placement in Distribution Networks Using Intelligent Systems, Energy, and Power Engineering. 4 (2012) 92-98. 